\title{
O MECANISMO E AS BASES INTELECTUAIS DA RE- VOLUÇÃO INDUSTRIAL INGLESA
}

\author{
Luiz Carlos Soares*
}

\section{UMA NOVA PERSPECTIVA DE ESTUDO PARA A REVOLUÇÃO INDUSTRIAL INGLESA}

Este artigo procura atingir dois grandes objetivos analíticos e interpretativos altamente relevantes para a renovação dos campos da História Econômica-Industrial e da História da Ciência e da Tecnologia. O primeiro deles pretende relacionar o processo de emergência da Revolução Industrial inglesa ao desenvolvimento da Concepção Científica Mecanicista, consagrada pela Física Newtoniana e pela Ilustração Francesa, que concebia a Natureza, o Mundo e o Universo a partir de uma ordem mecânica objetiva e exterior ao Homem. Já o segundo objetivo procura apresentar a aceitação e a disseminação da concepção Mecanicista nas Academias de Ensino "Dissidentes" ou "Não-Conformistas" da Inglaterra e em algumas Sociedades Científicas e Literárias desse país que, ao estimularem o estudo das Ciências e estabelecerem suas relações com as necessidades das indústrias, constituíram-se em influentes contrapontos às Universidades de Oxford e Cambridge, marcadas pelo oficialismo aristocrático e pela aceitação da Ortodoxia Anglicana, e, também, ao pouco dinamismo que a Royal Society of London apresentou na segunda metade do século XVIII.

Embora tenha sido grande o impacto das principais obras de Newton - os Princípios Matemáticos de Filosofia Natural e a Ótica -, não se pode deixar de mencionar a influência que as obras dos autores Ilustrados franceses exerceram sobre o meio intelectual britânico a partir dos anos 1740. Os "filósofos" da Ilustração retomaram a concepção de Ciência Racionalista e Mecanicista defendida, no século XVII, pelos diversos fundadores da

* ICHF/UFF. lcs@antares.com.br 
Ciência Moderna, mas o fizeram a partir de uma perspectiva bastante original que procurava estabelecer uma síntese entre duas concepções filosóficocientíficas distintas e divergentes: o Racionalismo Dedutivista de Descartes e o Mecanicismo Indutivista de Newton. Foi essa síntese da Ilustração que possibilitou a aceitação plena do Paradigma Racionalista-Mecanicista pelos meios intelectuais europeus e ocidentais no século XVIII e a hegemonia do seu projeto de Ciência até o início do século XX. ${ }^{1}$

Assim, na segunda metade do século XVIII, a Concepção Mecanicista de Mundo - fundamentada sobretudo no Mecanicismo Newtoniano - já estava consagrada nos meios intelectuais ingleses e franceses e, através da sua vulgarização e divulgação, tornou-se uma das poderosas alavancas intelectuais da grande transformação técnico-produtiva e social que se verificou na Inglaterra a partir dos anos 1780 - a Revolução Industrial. A disseminação do Mecanicismo nos meios técnicos e industriais, por sua vez, fundamentou a idéia de que o mundo da produção e, em particular, da produção industrial, poderia também se submeter à lógica da mecanização. ${ }^{2}$

Isso foi possível, primeiramente, porque a divulgação da Concepção Mecanicista de Mundo e dos princípios básicos da Física Newtoniana, através de manuais escritos durante o século XVIII, possibilitou que engenheiros, mecânicos, industriais e indivíduos com interesses na indústria pudessem também, através de sua prática, assimilar a lógica e alguns princípios da Ciência Moderna e empregá-los em suas atividades de desenvolvimento de máquinas e na formulação de uma nova organização técnico-industrial. Por outro lado, algumas Academias de Ensino "Dissidentes" ou "Não-Conformistas", como a Warrington Academy e a Manchester Academy, e Sociedades Científicas e Literárias, como a Lunar Society e a Literary and Philosophical Society of Manchester, não só foram

1 A Ilustração como um movimento de síntese intelectual é estudada por: CASSIRER, E. La filosofía de la Ilustración. México: Fondo de Cultura Económica, 1984. Outros estudos importantes sobre o movimento ilustrado, são: HAMPSON, N. The Enlightenment. An evaluation of its assumptions, attitudes and values. Londres: Penguin Books, 1990; GAY, P. The Enlightenment. The rise of modern paganism. Nova York: W. W. Norton \& Company, 1995; e HOF, U. I. The Enlightenment. Oxford: Blackwell Publishers, 1994. Sobre a problemática específica da Ciência na época das "Luzes", ver: HANKINS, T. L. Science and the Enlightenment. Cambridge-UK: Cambridge University Press, 1997.

2 Sobre a relação direta da divulgação da Física Newtoniana e de toda a cultura científica Mecanicista com as grandes transformações técnico-industriais ocorridas, primeiramente, na Inglaterra e, posteriormente, nos demais países europeus ocidentais, ver: JACOB, M. C. Scientific culture and the making of the industrial west. Oxford-New York: Oxford University Press, 1997. 
espaços de divulgação do Mecanicismo Newtoniano, como também, ao estimularem o estudo das Ciências Naturais e das suas relações com as necessidades das indústrias, contribuíram para a construção de uma visão de mundo material que assimilava a lógica da Concepção Mecanicista e a estendia à organização da vida produtiva, principalmente à indústria.

De modo geral, tanto a historiografia econômica como a historiografia científica relacionadas à Revolução Industrial Inglesa têm dado pouca, ou nenhuma, ênfase à relação das invenções de máquinas industriais e do próprio sistema fabril mecanizado com as grandes aquisições da Ciência no séculos XVII e XVIII. Inclusive, grandes estudiosos da Revolução Industrial, como Paul Mantoux, T. S. Ashton, Jean-Pierre Rioux, Eric J. Hobsbawm, David S. Landes e Peter Mathias (entre outros), ${ }^{3}$ afirmaram claramente que a Revolução Industrial teve pouca ou nenhuma relação com o ensino ou a pesquisa científica desenvolvidos por cientistas independentes ou nas duas grandes universidades, Oxford e Cambridge, que formavam as "elites" intelectuais, políticas e administrativas da Grã-Bretanha.

Eric Hobsbawm chegou a afirmar que as duas grandes universidades inglesas "eram intelectualmente nulas, como o eram também as sonolentas escolas públicas, com a exceção das Academias fundadas pelos dissidentes que foram excluídas do sistema educacional (anglicano)". Além dessas "Academias Dissidentes", as deficiências do ensino inglês também eram compensadas "pelas universidades democráticas, turbulentas e austeras da Escócia Calvinista, que lançavam uma corrente de jovens racionalistas, brilhantes e trabalhadores, em busca de uma carreira no sul do país", entre os quais estavam James Watt, Thomas Telford, Loudon McAdam e James Mill. ${ }^{4}$

Para Hobsbawm, a Revolução Industrial ou a constituição da "primeira economia industrial de vulto" deu-se de "modo bastante empírico, não planificado e acidental". ${ }^{5}$ Embora reconhecesse o maior dinamismo no ensino das universidades da Escócia Calvinista ou das "Academias

3 Ver: MANTOUX, P. La révolution industrielle au XVIIIe. siècle. Paris: Génin, 1959; ASHTON, T. S. A revolução industrial. 1760-1830. Lisboa: Publicações Europa-América, 1977; RIOUX, J. P. A revolução industrial: 1780-1880. São Paulo: Pioneira, 1975; HOBSBAWM, E. J. A era das revoluções: 1789-1848. Rio de Janeiro: Paz e Terra, 1977; LANDES, D. S. Prometeu desacorrentado. Transformação tecnológica e desenvolvimento industrial da Europa Ocidental, desde 1750 até a nossa época. Rio de Janeiro: Nova Fronteira, 1994; e MATHIAS, P. The first industrial nation. An economic history of Britain, 1700-1914. Londres-Nova York: Routledge, 1983.

4 Cf. HOBSBAWM, op. cit., p. 46-47. 
Dissidentes" inglesas, esse grande historiador inglês não procurou estabelecer nenhum nexo entre essas instituições de ensino e as invenções técnicas que caracterizaram o processo de emergência da Revolução Industrial. Sobre essas invenções, Hobsbawm afirmou enfaticamente:

Felizmente poucos refinamentos intelectuais foram necessários para se fazer a revolução industrial. Suas invenções técnicas foram bastante modestas, e sob hipótese alguma estavam além dos limites de artesãos que trabalhavam em suas oficinas ou das capacidades construtivas de carpinteiros, moleiros e serralheiros: a lançadeira, o tear, a fiadeira automática. Nem mesmo sua máquina cientificamente mais sofisticada, a máquina a vapor rotativa de James Watt (1784), necessitava de mais conhecimentos de física do que os disponíveis então há quase um século - a teoria adequada das máquinas a vapor só foi desenvolvida ex post facto pelo francês Carnot na década de 1820 - e podia contar com várias gerações de utilização, prática de máquinas a vapor, principalmente nas minas. Dadas as condições adequadas, as inovações técnicas da revolução industrial praticamente se fizeram por si mesmas, exceto talvez na indústria química. Isto não significa que os primeiros industriais não estivessem constantemente interessados na ciência e em busca de seus benefícios práticos. ${ }^{6}$

Essa parece ser também a opinião de David S. Landes, ao falar sobre algumas invenções importantes que marcaram a Revolução Industrial e sua pouca relação com um desenvolvimento mais "teórico" da Ciência:

Afirma-se com frequiência que a máquina de Newcomen e suas precursoras teriam sido impensáveis sem as idéias teóricas de Boyle, Torricelli e outros; e que Watt extraiu grande parte de sua competência e imaginação técnicas de seu trabalho com cientistas e instrumentos científicos em Glasgow. Há, sem dúvida, alguma verdade nisso, embora seja impossível dizer quanta. Uma coisa é certa, porém: uma vez estabelecido o princípio do condensador separado, os avanços subseqüentes deveram pouco ou nada à teoria. Ao contrário, um ramo inteiro da física, a termodinâmica, desenvolveu-se, em parte, como resultado das observações empíricas e dos métodos e do desempenho da engenharia. Tampouco foi por acidente que esse trabalho teórico iniciou-se na França, onde uma escola como a Polytechnique

5 Cf. HOBSBAWM, op. cit., p. 68.

6 Ibid., p. 46-67; grifos do autor. 
esforçava-se, explicitamente, para enquadrar a técnica em generalizações matemáticas. Mas nada disso impediu a Inglaterra de continuar a liderar o mundo na prática e nas invenções da engenharia. ${ }^{7}$

Argumentos como esses têm sido repetidos sistematicamente e a articulação do processo de emergência da Revolução Industrial, com fatores da ordem intelectual, tem sido negligenciada e estabelecida unicamente com fatores de natureza econômica, entre os quais se destacam: 1) a ampliação do comércio mundial e o domínio dos oceanos pela marinha britânica, que estimularam o aumento da produção industrial e as invenções das máquinas; 2) o fechamento dos campos ingleses (enclousures), que foi responsável pelo processo de proletarização dos trabalhadores rurais e pela formação potencial do exército de mão-de-obra industrial; 3) a abundância do carvão britânico, que possibilitou a produção da energia a vapor para a movimentação do maquinismo.

Sem negar a importância dos fatores da ordem econômica, a pesquisa proposta será direcionada para uma outra perspectiva, fundamental para a grande transformação técnico-produtiva representada pela Revolução Industrial, que introduziu não somente uma nova organização do processo de produção industrial, com a fábrica mecanizada, mas o próprio sistema ou modo capitalista de produção. Esta perspectiva leva em consideração $a$ importância da construção de uma concepção mecanicista do mundo social e produtivo, processo este lentamente estabelecido no decorrer do século XVIII. A construção dessa concepção não se deu, evidentemente, nas conservadoras e "sonolentas" universidades inglesas, como afirmou Hobsbawm, mas em diferentes instituições e espaços da sociedade, que assimilavam, sobretudo, a tradição racional-experimental e indutivista da Ciência britânica, predominante desde o século XVII, e também a produção filosófica, científica e literária da Ilustração francesa.

Essa perspectiva, numa crítica direta a nomes consagrados da historiografia econômica e social, é desenvolvida por Margaret C. Jacob, que afirma:

O conhecimento mecânico e matemático possuído por engenheiros e homens de negócios britânicos, e mesmo por artesãos como aqueles que pertenciam à Sociedade dos Engenheiros Civis, originou-se em cursos dados por professores

7 Cf. LANDES, op. cit., p. 109-110. 
viajantes, a partir de um paciente estudo de manuais baseados nos Principia, em compêndios de mecânica prática ou manuais usados em academias privadas formadoras de artesãos, ou no comparecimento regular às sessões de sociedades voluntárias como a Lunar, em Birmingham, a Literária e Filosófica, em Manchester, e mesmo a Royal Society, em Londres. ${ }^{8}$

Margaret C. Jacob faz questão, ainda, de mencionar os nomes de dois grandes divulgadores da Física Newtoniana, Francis Hauksbee e Jean Desaguliers, que, na primeira metade do século XVIII, escreveram importantes manuais que tornaram, já em meados do século XX, “o conhecimento mecânico aplicado disponível para qualquer um que fosse sumamente alfabetizado em Inglês e depois em Francês e Holandês". O livro de Hauksbee, publicado em 1719 e intitulado Physico-Mechanical Experiments in Various Subjetcs ... (Experimentos de Físico-Mecânica em Diversos Assuntos ...), era um resultado de suas aulas e conferências que foram consideradas, na Inglaterra, como os primeiros ensinamentos de mecânica aplicada realmente baseados nos Principia de Newton e nas suas "leis gerais de atração e repulsão, comuns a toda matéria". Desaguliers, por seu turno, chegou a ser considerado como o "Newtoniano" mais famoso nos anos 1720 e 1730 e obteve grande parte do seu conhecimento teórico e prático como "experimentador oficial" da Royal Society, deixando esta função por outra mais lucrativa, que era a de ministrar cursos de dez semanas sobre a Física Newtoniana e suas possibilidades de aplicação, para homens e mulheres que pagavam uma taxa de inscrição de dois guinéus. O resultado dessas aulas foi reunido num manual intitulado A Course of Experimental Philosophy (Um Curso de Filosofia Experimental, publicado inicialmente em 1734 e revisado e ampliado em 1744), que se tornou uma obra de consulta quase obrigatória para todos os interessados na aplicação industrial dos princípios mecânicos, pneumáticos, hidrostáticos e hidrodinâmicos anunciados pela Física Newtoniana. ${ }^{9}$

A divulgação da Física Newtoniana em manuais utilizados por industriais e mecânicos, no século XVIII, tem sido um outro aspecto pouco assinalado pelos estudiosos da Revolução Industrial. Embora industriais e mecânicos estivessem distantes das grandes discussões intelectuais e científicas da época, que levaram a Física Newtoniana à posição de paradigma e modelo de conhecimento, esses profissionais não só tiveram acesso aos princípios da Mecânica Newtoniana, através da leitura de livros que

8 Cf. JACOB, op. cit., p. 110.

9 Ibid., p. 106 e 110-111. 
procuravam traduzir em linguagem simples e prática esses princípios, como também deles se utilizaram para a construção de suas máquinas e a reorganização do processo de produção industrial. Esta é uma outra dimensão bastante rica da fundamentação intelectual da Revolução Industrial que poderá ser explorada para se conhecer esse processo na sua globalidade.

Dando sequiência às suas reflexões originais, Margaret C. Jacob procura enfatizar a relação entre os princípios experimentais da Física Newtoniana e a formação de uma cultura científica aplicada, divulgada entre os engenheiros, industriais e artesãos letrados, que se constituiu, de fato, numa das alavancas intelectuais da Revolução Industrial inglesa:

O engenheiro civil ou o mecânico britânico do século dezoito, uma figura meramente profissional, freqüentemente autodidata e autoretratado por pioneiros como Jean Desaguiliers, John Smeaton e James Watt, é a figura central do aspecto cultural da história discutida neste capítulo ["As Origens Culturais da Primeira Revolução Industrial”]. Graças à cultura científica estabelecida na Inglaterra por volta de 1700, estes homens adquiriram o conhecimento necessário para efetuar os cálculos mais avançados requeridos para mover objetos pesados sobre terrenos montanhosos ou de dentro das profundas minas de carvão nunca antes alcançadas. Os engenheiros e homens de negócios britânicos que procuraram construir ou melhorar os canais e portos e inventar, como também usar, máquinas a vapor, tinham que estar aptos para entender um ao outro. (...) A cultura científica ancorada em torno da Síntese Newtoniana forneceu o vocabulário prático e cada vez mais acessível. ${ }^{10}$

Embora muito mais próximo da posição de Eric Hobsbawm e David Landes, ao dizer que as inovações da época da Revolução Industrial "não eram o resultado da aplicação formal da ciência aplicada, nem um produto do sistema de educação formal do país", ${ }^{11}$ o historiador Peter Mathias fornece, por outro lado, algumas evidências que corroboram as preocupações de Magaret C. Jacob e as que são apresentadas neste artigo. Ao colocar James Watt, o Dr. John Roebuck e alguns químicos como as poucas exceções em relação ao "arquétipo tradicional" dos construtores da primeira Revolução Industrial, Mathias afirma:

10 Cf. JACOB, op. cit., p. 106.

11 Cf. MATHIAS, op. cit., p. 124. 
James Watt foi um produto soberbo do mundo universitário escocês. Ele acompanhou as aulas de Joseph Black sobre o calor latente na Universidade de Glasgow. Ele realizou experimentos específicos sobre a elasticidade do vapor e a condutividade dos metais. Porém, uma dúzia ou mais de inventores e aperfeiçoadores de técnicas em energia a vapor, e todo o pioneirismo das máquinas de alta pressão, vieram da tradição amadora e dos ferreiros. Alguns dos industriais e inovadores na indústria de descoloração, onde o ácido sulfúrico tornou-se a base do processo, e em outros ramos da indústria química, eram químicos formados como tais, como o famoso Dr. Roebuck, que esteve envolvido em muitos negócios, embora seu doutorado, na realidade, fosse em medicina. Geralmente, estes títulos eram obtidos em universidades escocesas ou continentais. Os industriais começaram a usar cada vez mais instrumentos de medição científica como termômetros e hidrometros, reduzindo o empirismo de suas práticas e orientando-as quando possível. Atitudes científicas, como experimentação, observação, prova, eram muito mais difundidas do que o conhecimento científico. Porém, os exemplos individuais de inovações pioneiras de químicos formados, ou a utilização destes pelos industriais, para assessorá-los, não forma uma seleção representativa. Isso foi comprovado certamente depois de meados do século dezenove quando o governo se deu conta de que quase nenhum químico formado existia no país, para produzir uma torrente de inovações com base na ciência aplicada, e uma crise nacional a este respeito foi revelada com a eclosão da guerra, em 1914. ${ }^{12}$

Realmente, se houve uma preocupação dos industriais com a necessidade de adoção de uma prática mais orientada cientificamente (com a utilização de instrumentos de medição ou precisão) isso evidencia uma mudança de atitude em relação às práticas simplesmente empíricas ou rotineiras. Além disso, torna-se muito difícil estabelecer uma rígida separação entre as "atitudes científicas" e o "conhecimento científico", como quer Peter Mathias. Se os industriais ou os inventores pioneiros passam a se utilizar sistematicamente da experimentação, observação e prova, isso mostra que eles procuravam se basear em fundamentações científicas para atingir os seus objetivos de desenvolvimento de novas técnicas produtivas que reduzissem os custos de seus estabelecimentos, sobretudo com a mão-deobra assalariada, e aumentassem a sua produtividade e lucratividade. Objetivamente, pode-se dizer que, embora a Revolução Industrial não tenha

12 Cf. MATHIAS, op. cit., p. 125; grifos meus. 
produzido uma nova Ciência ou um novo conjunto de concepções científicas, ela se ancorou, de modo concreto, na Ciência que vinha sendo produzida desde o final do século XVII.

Na segunda metade do século XVIII, foram instituições como as Academias "Não-Conformistas", as Sociedades Científicas e Literárias provinciais e as Universidades da Escócia Calvinista que procuraram dar um maior dinamismo ao desenvolvimento das Ciências Naturais na Grã-Bretanha, apontando claramente para uma vinculação direta dessas Ciências com as necessidades das indústrias no sentido da utilização de novas técnicas que aumentassem a sua produtividade e a lucratividade e estabelecessem novos horizontes econômicos. Por outro lado, não podemos esquecer que essas Ciências Naturais já estavam marcadas pela aceitação plena dos paradigmas epistemológicos da Física Newtoniana, tanto pela via tradicional do Empirismo-Indutivista britânico, como através do diálogo que muitos cientistas ingleses e escoceses mantiveram com a Ilustração francesa.

Além disso, os "Filósofos" da Ilustração francesa, principalmente Voltaire, passaram a desenvolver uma compreensão da organização da sociedade também baseada numa idéia de ordem regular, constituída por leis invariantes, inspirada na Física Newtoniana e na idéia de existência de uma ordem natural mecânica e universal, exterior e anterior ao Homem. ${ }^{13}$ Isso significa que a sociedade também passou a ser encarada de forma objetiva, quer dizer, como um objeto que tem a sua própria ordem ou lógica que se caracteriza pela exterioridade e anterioridade em relação aos interesses e às paixões dos sujeitos individuais que a constituem. Essas idéias também tiveram grande aceitação nos meios intelectuais "Não-Conformistas" da Inglaterra e da Escócia Calvinista, contribuindo para a formação do pensamento liberal britânico na segunda metade do século XVIII, cujos setores mais eruditos participavam de instituições científicas e literárias provinciais, como a Lunar Society e a Literary and Philosophical Society of Manchester, sem deixar de mencionar a Philosophical Society of Edinburgh, no maior centro cultural da Escócia. ${ }^{14}$

Assim, se a sociedade passou a ser concebida dentro da mesma lógica estabelecida pela idéia da "Machina-Mundi" Newtoniana, nada mais

13 Sobre a influência da Física Newtoniana no pensamento de Voltaire e da Ilustração francesa, ver: CASINI, P. Newton e a consciência européia. São Paulo: Unesp, 1995.

14 Sobre a divulgação das idéias da Ilustração francesa na Inglaterra e na Escócia, ver: HAMPSON, op. cit.; e BROADIE, A. (Org.) The Scottish Enlightenment. An anthology. Edimburgo: Canongate Books, 1997. 
natural que esse Mecanicismo Social fosse estendido ao mundo da produção da vida material. Adam Smith, em A Riqueza das Nações, expressou muito bem essa compreensão ao falar que o "mercado" tem as suas próprias leis, independentes da vontade humana individual. Desse modo, da invenção das primeiras máquinas industriais até a adoção do sistema integrado e concentrado de máquinas - a fábrica -, já no início do século XIX, desenvolveu-se a idéia da naturalização de uma produção industrial mecanizada e essa foi uma das importantes alavancas intelectuais do processo que desencadeou a Revolução Industrial inglesa.

Por enquanto, este trabalho explorará apenas a trajetória das duas mais importantes Academias "Dissidentes" de Ensino (Warrington Academy e Manchester Academy, depois Manchester College) e das duas mais renomadas sociedades científicas e literárias (Lunar Society e Literary and Philosophical Society of Manchester) da Inglaterra na segunda metade do século XVIII e início do século XIX. Essa exploração se fará, evidentemente, com base nas idéias gerais acima apresentadas, que deverão funcionar, sobretudo, como um referencial hipotético para o desenvolvimento das futuras investigações.

\section{AS ACADEMIAS "DISSIDENTES" DE ENSINO}

Enquanto as Universidades de Oxford e Cambridge congelaram os ensinamentos da Física Mecanicista Newtoniana - talvez até mesmo pelo peso que a genialidade de Newton representou para as gerações posteriores -, esquecendo-se de seus aspectos elementares como o caráter instrumental e experimental da nova Ciência, as "Academias Dissidentes" ou "NãoConformistas" retomaram esse pressuposto, desenvolvendo-o como uma de suas bases para um ensino que, além das disciplinas mais gerais e das humanidades, dirigia-se para a vida prática e para o mundo dos negócios. Não era raro que nessas instituições - muitas delas localizadas nas tradicionais regiões industriais das Midlands (Centro da Inglaterra) ou do Norte -, houvesse a tentativa de se estabelecer uma filosofia de ensino que vinculasse as Ciências às necessidades dos ramos industriais mais importantes.

Esses "Dissidentes" ou "Não-Conformistas" eram homens profundamente ligados às várias seitas protestantes que se constituíram no século XVI e, em meados do século XVII (1648-1660), promoveram a "Revolução Puritana", que aboliu a monarquia e conduziu Oliver Cromwell ao poder. Após a Restauração da Monarquia e da dinastia Stuart, o Rei 
Carlos II tentou obrigar as diversas seitas a se conformarem às exigências do "Act of Uniformity" ("Ato de Uniformidade") de 1662, que procurava estabelecer uma padronização religiosa a partir do Anglicanismo. Essas seitas se recusaram a fazê-lo, sendo seus membros chamados, a partir daí, de "Dissidentes" ("Dissenters") ou "Não-Conformistas" "Non-Conformists"). Entre as seitas "Dissidentes", que conservaram muito de sua antiga atitude anti-aristocrática, sobressaíram-se os Quakers e os Presbiterianos, que, se no século XVII tinham uma composição social de indivíduos provenientes das camadas mais pobres da sociedade, no século XVIII, seus membros provinham basicamente da "classe média", ou "burguesia", vinculada à indústria, principalmente à indústria do ferro, e desempenharam um importante papel no processo da Revolução Industrial.

Um outro historiador inglês Stephen F. Mason, mais sensibilizado com a relação entre os aspectos intelectuais e culturais e o processo da Revolução Industrial, traçou muito bem um perfil dos Quakers:

Os Não-Conformistas eram proeminentes particularmente no desenvolvimento das indústrias pesadas, tal como a indústria do ferro. Os Quakers dominaram praticamente todo este ramo durante o século XVIII, enquanto que os donos das indústrias de ferro anglicanos procuravam comprar propriedades rurais e tornar-se nobres, deixando o ramo para os Quakers que, rejeitando o princípio aristocrático da hereditariedade, não aspiravam integrar-se à nobreza territorial. ${ }^{15}$

Entretanto, os Presbiterianos (denominação que tiveram os Calvinistas da Inglaterra e da Escócia), como defendiam de modo mais firme o princípio da "razão", além das liberdades civis e religiosas, podiam ser considerados como os autênticos "Dissidentes Racionalistas", ao contrário dos "Protestantes Evangélicos" (Metodistas, Batistas, Anabatistas etc.) e de suas diversas "teorias" ("a corrupção total e inata ao gênero humano" e, por conseqüência, a "reprovação", a "expiação"). As congregações Presbiterianas se dividiam em dois grupos: os "Socinianos" e os "Arianos". Os primeiros defendiam uma interpretação "Anti-Trinitária" das sagradas escrituras, enquanto que os últimos interpretavam a pessoa de Cristo colocando-o numa posição abaixo do "Pai" na hierarquia divina, mas que ainda era distinta e de maior importância do que a posição de todas as outras

15 Cf. MASON, S. F. A history of sciences. Nova York: Collier Books, 1962.

p. 285 . 
"criaturas". No final do século XVIII, as posições "Anti-Trinitárias", defendidas inicialmente pelo "Socinianos", passaram a afirmar com maior radicalidade a "total humanidade" de Cristo e a "unipersonalidade" de Deus, em consonância com as novas idéias de religiosidade (a busca de uma "Religião Racional") defendida pelos filósofos da Ilustração, dando origem à corrente "Unitarista", cujo maior porta-voz foi Joseph Priestley. Os "Unitaristas" defendiam também uma perspectiva de maior radicalidade no que se relacionava às questões da liberdade religiosa, da liberdade de pensamento e da igualdade dos direitos civis, aproximando-se dos princípios revolucionários surgidos na França e constituindo-se, por isso, nos arautos do Liberalismo Democrático britânico. ${ }^{16}$

Como os "Não-Conformistas" estavam proibidos de cursar as Universidades de Oxford e Cambridge, foram, assim, obrigados a fundar os seus próprios estabelecimentos de ensino, alguns dos quais ligados, sobretudo, aos Presbiterianos e, durante o século XVIII, chegaram a ter um padrão de ensino universitário, com um currículo mais adaptado às necessidades da época e incluindo os objetos mais importantes das modernas Ciências. Inclusive, muitas famílias Anglicanas, entediadas com o conservadorismo do sistema educacional britânico, chegaram a mandar seus filhos para as Academias "Não-Conformistas". Entre essas instituições, distinguiram-se a Warrington Academy (Academia de Warrington) e a Manchester Academy (Academia de Manchester) e nelas ensinaram, respectivamente, Joseph Priestley e John Dalton, cientistas de grande reputação na segunda metade do século XVIII e início do XIX.

De certo modo, as academias de Warrington e Manchester foram herdeiras de importantes instituições "Dissidentes" de ensino, fundadas pelos Presbiterianos no Norte da Inglaterra, na primeira metade do século XVIII, tais como as academias de Whitehaven-Bolton, Attercliffe (Sheffield), Kendal e Findern (Derbyshire), que fecharam as suas portas (respectivamente, em 1729, 1734, 1753 e 1754) devido sobretudo à falta de recursos. Essas academias particulares já se notabilizavam por uma concepção de ensino inovadora e uma perspectiva teológica e religiosa racionalista e mais liberal.

16 Cf. Manchester College Oxford. Chronology of antecedents and development, 1786-1986; WEBB, R. K. The Unitarian Background. In: SMITH, B. Truth, liberty, religion. Essays celebrating two hundred years of Manchester College. Oxford: Manchester College Oxford, 1986. p. XIX-XX e 1-30; HAMPTON, D. Arianism. In: BLACK, J.; PORTER, R. A dictionary of eighteenth-century world history. Oxford: Blackweel Publishers, 1994; e DITCHFIELD, G. M. Unilateralism. In: BLACK; PORTER, op. cit., p. 35 e 748 . 
Todavia, com o fechamento destas instituições de ensino, setores importantes da "Comunidade Presbiteriana" do Norte da Inglaterra sentiram a necessidade da criação de uma nova instituição que não fosse "propriedade" de um único indivíduo e tivesse a importante tarefa de formação intelectual dos jovens "Dissidentes Racionalistas" e dos seus futuros ministros religiosos, com base numa filosofia que defendia a igualdade de direitos civis e a liberdade religiosa e de pensamento. ${ }^{17}$

Entretanto, a atuação do Reverendo John Seddon foi fundamental para que se criasse, em 1757, na cidade de Warrington (quase a meio caminho entre Manchester e Liverpool, às margens do Rio Mersey), uma nova academia com recursos oriundos das subscrições obtidas na própria "Comunidade Dissidente". Foi Seddon que organizou as primeiras reuniões entre os "Dissidentes" com maior potencial para financiar as atividades da nova academia, que tornaram-se seus subscritores anuais ("Trustees"), e, logo, foi constituído o Conselho de Diretores da instituição. Por esse esforço, Seddon foi apontado, pelo Conselho Diretor, como o Secretário da academia, sendo Arthur Heywood (de uma família de comerciantes e banqueiros de Liverpool) indicado seu Secretário e o 15. ${ }^{\circ}$ Barão de Parham, Lorde Hugh Willoughby, que era o último representante das famílias aristocráticas Presbiterianas, escolhido como seu primeiro Presidente. O Lord Willoughby também era, na ocasião, Vice-Presidente da Royal Society of London e VicePresidente da Society for the Encouragement of Arts (Sociedade para o Incentivo às Artes). Posteriormente, em 1767, Seddon, em reconhecimento pelo seu trabalho, foi apontado pelo Conselho diretor como Rector Academiae (Reitor da Academia), cargo este que conservou até a sua morte (1770), sendo substituído pelo Dr. William Einfield. ${ }^{18}$

Os primeiros tutores da academia foram os professores John Taylor (Doutor em Teologia pela Universidade de Glasgow) e John Aikin (Doutor em Teologia pela Universidade de Abeerden), evidenciando claramente o forte elo de ligação da intelectualidade "Não-Conformista" com as universidades da Escócia e os principais nomes do movimento iluminista escocês. O próprio Secretário, John Seddon, mesmo sem uma trajetória

17 Cf. MACLACHLAN, H. Warrington Academy: its history and influence. Manchester: Chetham Society, 1943. p. 11.

18 Cf. TURNER, W. The Warrington Academy: 1757-1786. Warrington: Library and Museum Committee, 1957. p. 3-11 e 30-35 (o autor foi aluno da academia e tornou-se, após a sua formatura, um ministro religioso "Dissidente", publicando originalmente este trabalho, entre 1813 e 1815, como uma série de artigos, no periódico Monthly Repository); e MACLACHLAN, op. cit., p. 11-14. 
intelectual tão brilhante como a dos dois primeiros tutores, como aluno da Universidade de Glasgow, teve uma enorme influência dos filósofos Hutcheson e Leechman. Mais tarde, com a ampliação da academia, foram incorporados outros Tutores, como Joseph Priestley e William Enfield, que obtiveram seus títulos de doutorado na Universidade de Edimburgo.

Segundo as próprias palavras do Secretário da Warrington Academy, o principal objetivo educacional dessa instituição era "implementar o progresso da verdadeira religião e a liberdade religiosa" ${ }^{19}$ Mas, foi um de seus primeiros tutores, o Dr. John Taylor, com o seu livro-texto Scheme of Scripture Divinity (Esquema da Teologia das Escrituras), quem melhor divulgou a filosofia educacional da academia, baseada claramente no ideário "Whig" ${ }^{20}$ e nos princípios do Liberalismo Democrático nascente. Inicialmente, esse livro foi preparado pelo Dr. Taylor para o uso exclusivo dos alunos de Warrington, mas publicado comercialmente depois da sua morte, tendo como conteúdo os diversos assuntos explorados nas suas aulas de Teologia. Essas aulas eram prefaciadas pelo Dr. Taylor com uma espécie de "encargo solene" aos seus alunos, em que os princípios da liberdade religiosa, da liberdade de pensamento, da valorização da razão e da igualdade de direitos eram plenamente afirmados:

Eu solenemente vos encarrego, em nome do Deus da Verdade, e de Nosso Senhor Jesus Cristo, que é o caminho, a verdade e a vida, e diante de cujo juízo, vós deveis mostrar, sem nenhuma demora, $1^{\circ}$.) que em todos os vossos estudos e indagações de natureza religiosa, presentes ou futuros, vós dareis constante, cuidadosa, imparcial e conscientemente atenção à evidência, como está nas sagradas escrituras, ou na natureza das coisas, e nos ditados da razão; prudentemente protegidos contra as investidas da imaginação, e da falácia da mal-fundamentada conjectura. $2^{\circ}$.) Que vós não admitireis, abraçareis e consentireis nenhum princípio ou juízo, por mim ensinado ou adiantado, exceto quando, na vossa opinião, ele se mostrar apoiado e justificado pela própria evidência da revelação, ou pela razão das coisas. $3^{\circ}$.) Que se, futuramente, algum princípio ou juízo por mim ensinado ou adiantado, ou por vós admitido ou abraçado, que, na vossa opinião, mostrar-se dúbio ou falso, a partir de um

19 Cf. MACLACHLAN, op. cit., p. 16.

20 Termo que se refere aos Presbiterianos da Escócia e aos membros do partido político que, na Inglaterra, depois da "Revolução Gloriosa" de 1688-89, procurou subordinar o poder da Coroa e das "classes superiores" (aristocracia) ao Parlamento e defendiam um Regime Monárquico Parlamentar. 
exame imparcial e fiel, vós devereis suspeitar ou rejeitar totalmente tal princípio ou juízo. $4^{\circ}$.) Que vós mantereis vossas mentes sempre abertas à evidência; que vós vos esforçareis para banir de vossos sentimentos todo o preconceito, prepotência, e partidarismo; que vós estudareis para viver em paz e amor com vossos semelhantes cristãos; e que vós sustentareis firmemente para vós mesmos, e livremente permitireis para outros, os direitos inalienáveis de opinião e consciência. ${ }^{21}$

De acordo com o "Plano de Educação" da Warrington Academy, o "curso completo", destinado para aqueles que pretendiam exercer o ministério religioso, tinha uma duração de 5 anos, mas existia um "curso especial", com a duração de 3 anos, para os jovens que "aspiravam por uma vida de Negócio ou Comércio". A grande maioria dos estudantes começava a cursar a academia com a idade de 14 anos e tinha uma clara preferência pelo curso de 3 anos, que servia como uma excelente preparação para a entrada nos diversos cursos das universidades escocesas, da Universidade de Leyden (Holanda) e, em pouquíssimos casos, das universidades Anglicanas (Cambridge e Oxford). Para o curso de 3 anos, o "Plano de Educação" de Warrington estabelecia as seguintes disciplinas e atividades:

Primeiro Ano:

1) Matemática Elementar (Aritmética, Álgebra e Geometria).

2) Francês. 3) Gramática Universal e Retórica. Exercícios Semanais: 1) Tradução do Francês para Inglês. 2) Composição de um ensaio sobre um assunto em Inglês. 3) Reprodução de diversos tipos de cartas no estilo epistolar.

Segundo Ano:

1) Matemática (Trigonometria; Navegação, se desejada). 2) Filosofia Natural, e "as partes mais fáceis da Astronomia aplicada para o uso de Globos e o sistema geral do Universo". 3) Francês. Exercícios Semanais: 1) Tradução do Inglês para o Francês. 2) Reprodução de diversos tipos de cartas em Francês. 3) Composição em Inglês.

Terceiro Ano:

1) Filosofia Natural e "alguns dos principais Experimentos nos Elementos de Química”. 2) "Um pequeno sistema de Moral (...)

21 Cf. TURNER, op. cit., p. 10-11. 
concluindo com as Evidências da religião Cristã”. Exercícios Semanais: 1) Dissertações sobre alguns assuntos políticos e comerciais. 2) Traduções Francês-Inglês e Inglês-Francês. ${ }^{22}$

Entre 1757 e 1782, ingressaram na Warrington Academy cerca de 400 estudantes, provenientes dos mais diferentes pontos da Inglaterra, mas, em sua maioria, das regiões do Norte. Embora tivesse seus objetivos mais diretamente vinculados com a formação dos jovens "Dissidentes" e a preparação dos ministros religiosos presbiterianos, a academia estava aberta ao público em geral, chegando a receber, inclusive, jovens oriundos de famílias Anglicanas, constituindo-se, por isso, como uma das primeiras e mais inovadoras "public schools" ("escolas públicas") da Inglaterra. ${ }^{23}$

Entre os mais famosos e brilhantes alunos da Warrington Academy, estavam: Thomas Percival, médico famoso de Manchester que foi o primeiro presidente da Sociedade Literária e Filosófica, fundada em 1781 naquela cidade; William Turner, religioso e professor da Manchester Academy, sucessora de Warrington, que escreveu uma primeira história dessa academia; Thomas Potter, grande comerciante de Manchester; Matthew Nicholson, grande comerciante de Liverpool; William Bancroft, proprietário de uma fábrica de seda em Stockport; Snowden White, médico de Nothingham e um dos maiores defensores da liberdade civil e religiosa para os "Não-Conformistas" ingleses; John Milnes, grande comerciante em West Ridind e em todo o Yorkshire; Joseph Robinson, grande banqueiro de Manchester; Samuel Crompton, grande banqueiro em Derby e York; John Prior Estlin, eminente religioso "Não-Conformista"; Richard e Benjamin Heywood, filhos do tesoureiro, Arthur Heywood, que sucederam o pai à frente dos negócios comerciais e bancários da família, em Liverpool; Benjamin Vaugham, advogado famoso que chegou a ser membro do parlamento e era filho de Samuel Vaugham, um importante comerciante das "Indias Ocidentais"; George

22 Cf. MACLACHLAN, op. cit., p. 40.

23 As "public schools" da Inglaterra não podem ser confundidas com as "escolas públicas" dos países latinos que passaram a ser financiadas pelos poderes públicos (Estado). As "public schools" inglesas, financiadas por comunidades religiosas ou sociedades civis e abertas a um "público" formado por alunos de diversas origens religiosas, diferenciavam-se das "private schools" ("escolas privadas") - que eram praticamente conduzidas por um único professor, seu proprietário, encarregado de todas as disciplinas, ministradas para um grupo reduzido ou específico de alunos - e, a partir do século XIX, das "government schools" ("escolas governamentais") - também abertas ao público em geral, mas financiadas pelo Estado. 
Willoughby, 17..$^{\circ}$ Barão de Parham, residente nas cercanias de Rivington (Lancashire), filho do Lorde Hugh Willoughby, que foi presidente da academia; Samuel Heywood, eminente advogado de Liverpool e defensor famoso da liberdade civil e religiosa para os "Não-Conformistas"; Samuel Galton, grande comerciante e industrial de Birmingham, membro da Lunar Society; Samuel Shore, importante militante da causa da liberdade civil e religiosa dos "Não-Conformistas", que chegou a ser diretor do Manchester College, em York, que sucedeu a Manchester Academy; John Goodricke, matemático e astrônomo famoso, residente em York e Thomas R. Malthus, o famoso economista político, residente em Cookham. ${ }^{24}$

A Warrington Academy funcionou até 1783, quando, em função de sérios problemas disciplinares de seus alunos, das suas dificuldades financeiras e de uma administração pouco eficiente, não houve o ingresso de novos alunos oriundos da "Comunidade Dissidente", cujos pais se sentiam inseguros em colocar seus filhos numa instituição de ensino que vivia numa situação de crise. Naquele ano, o corpo docente da academia se dissolveu e, embora tenham se dado algumas tentativas de revitalização da instituição, ela fechou suas portas definitivamente em 1786, no mesmo ano em que a "Comunidade Não-Conformista" criou uma nova instituição de ensino na cidade de Manchester, que se tornou herdeira direta da biblioteca e de toda a tradição de ensino de Warrington, utilizando-se, inclusive, do mesmo "Plano de Estudos" dessa instituição. ${ }^{25}$

Como sua antecessora, a Manchester Academy, embora objetivasse também a formação de jovens Presbiterianos, inclusive para o ministério religioso, não impunha nenhuma restrição de credo aos seus alunos e nos seus folhetos de divulgação afirmava, enfaticamente, o princípio da liberdade religiosa e o oferecimento, ao público, de um completo "curso de educação liberal", tal como num documento de 22 de fevereiro de 1786, em que era anunciada a fundação da nova instituição de ensino:

Uma reunião muito respeitável de Cavalheiros foi realizada neste dia 22 de fevereiro de 1786, quando foi unanimemente concordado, após a devida deliberação, que uma ACADEMIA devia ser estabelecida em MANCHESTER, sob um plano para fornecer um completo e sistemático Curso de Educação para RELIGIOSOS, e instruções preparatórias para as OUTRAS PROFISSÕES ERUDITAS, como também para a vida CIVIL e COMERCIAL. Esta Instituição estará aberta para jovens de

24 Cf. TURNER, op. cit., p. 51-79.

25 Cf. MACLACHLAN, op. cit., p. 99-107. 
todos os credos religiosos, e não será deles exigido nenhuma prova ou confissão de fé. ${ }^{26}$

Na realidade, a Manchester Academy estava muito mais vinculada ao "Unitarismo", a corrente Presbiteriana mais radical, pertencendo à grande maioria dos subscritores da instituição ("trustees") a esta corrente. Além disso, a academia tinha profundas ligações com a Capela de Cross Street (Cross Street Chapel), que era uma importante congregação dos "Dissidentes Racionalistas" da cidade de Manchester, sendo oriundos dessa congregação a totalidade dos membros do Conselho Diretor da academia, que teve a presidência do Dr. Thomas Percival. É importante também frisar que os dois primeiros tutores da instituição (nomeados pelo Conselho Diretor), Thomas Barnes e Ralph Harrison, eram ministros da Capela de Cross Street. Todavia, mantendo a coerência com seus princípios fundadores, a Manchester Academy também empregou o Anglicano Charles Sanders, como tutor em Letras Clássicas, e o Quaker John Dalton, como tutor em Filosofia Natural e Matemática. ${ }^{27}$

Nos seus primeiros momentos, a Manchester Academy teve uma participação direta na vida política e cultural da cidade, refletindo o ideário do radicalismo "Unitarista" na defesa dos princípios da liberdade e tolerância religiosa e em importantes campanhas de reforma social e pela abolição do tráfico de escravos africanos. O presidente da academia, Thomas Percival, e o seu primeiro tutor, Thomas Barnes, também tinham participado, em 1781, da fundação da Literary and Philosophical Society of Manchester, que manteve uma estreita relação com a academia durante o período em que ela funcionou na cidade. Inclusive, aos alunos mais antigos - os "senior academics" - era permitido assistir às sessões da sociedade e "das suas mais instrutivas discussões". ${ }^{28}$

26 Cf. Manchester Academy - Printed record of the foundation meeting (n. 1). In: MANCHESTER COLLEGE. Manchester College, 1786-1986. A bicentenary exhibition organised by Manchester College Oxford at the Bodeleian Library. Oxford: Manchester College, 1986. p. 2; as palavras destacadas com letras maiúsculas estão no próprio texto original, em inglês.

27 Cf. MANCHESTER COLLEG, op. cit., p. xx-xxi; WYKES, D. Sons and subscribers: lay support and the college, 1876-1840. In: SMITH, op. cit., p. 31-78; WATTS, R. Manchester College and education. 1876-1753. In: SMITH, op. cit., p. 79110. Para uma apresentação mais sintética da trajetória e da atividade educacional desta instituição, ver: MANCHESTER COLLEGE, op. cit.; e MANCHESTER College: a short history, 1786-1900. Oxford: Manchester College, 1990.

28 Cf. MANCHESTER COLLEGE, op. cit.; MANCHESTER... op. cit., p. 7. 
Embora conservando o "Plano de Estudos" de Warrington, com um "curso especial" de 3 anos para os "leigos" e um outro curso de 5 anos para a formação dos ministros religiosos, a Manchester Academy desenvolveu um vínculo muito maior com o mundo dos negócios da já maior cidade industrial da Inglaterra, procurando, inclusive, ampliar o horizonte cultural dos futuros homens ligados à indústria, ao comércio e às finanças em geral, que, obviamente, optavam pelo primeiro curso de 3 anos. Isso se refletia na maior ênfase que as aulas de "Comércio", "Filosofia Natural" e "Ciências" possuíam no conjunto das disciplinas da Manchester Academy, sem que, no entanto, a formação moral e religiosa dos estudantes leigos fosse relegada a um segundo plano. O próprio Thomas Barnes foi encarregado das aulas de "Comércio", assim como da disciplina de "Teologia". Essa maior preferência dos alunos da academia pelo "curso especial" se reflete nos próprios registros da instituição que, entre 1786 e 1797, recebeu 135 estudantes (quase todos de Manchester), dos quais apenas 20 concluíram o curso para a formação de religiosos. ${ }^{29}$

Todavia, apesar da grande reputação que a Manchester Academy obteve, num curto espaço de funcionamento, essa instituição foi obrigada a fechar suas portas em 1803, em virtude de alguns sérios problemas, como a insuficiência dos fundos de financiamento, a indisciplina dos estudantes e a mudança freqüente no quadro de professores, que foram agravados pela perseguição que os Unitários sofreram depois das revoltas dos Anglicanos e Realistas contra os adeptos e simpatizantes da Revolução Francesa - as "Revoltas do Rei e de Deus" ("King and God Riots") -, ocorridas em 1791. $\mathrm{Na}$ realidade, este movimento ocorreu em diversas cidades inglesas, mas alcançou uma maior violência em Manchester e Birmingham, que eram dois grandes centros do pensamento liberal mais radical e democrático. A partir dessa reação conservadora, os Unitários foram perseguidos ou colocados sob suspeita de "traição à Deus e à Pátria" e o restante dos anos 1790 foi um período muito difícil para os integrantes dessa corrente Presbiteriana. Não resta a menor sombra de dúvida de que esse clima contribuiu para agravar os problemas da Manchester Academy e provocar a transferência da instituição de ensino Unitário, em 1803, para a cidade de York. ${ }^{30}$

Com a mudança para York, a instituição chegou, inclusive, a mudar de nome para Manchester College, verificando-se também uma completa reformulação do seu quadro de professores, permanecendo apenas George

29 Cf. RAYMOND; PICKSTONE, op. cit., p. 127-164; e MANCHESTER..., op. cit., p. 9.

30 Cf. WYKES, op. cit., p. 9. 
Walker, um dos últimos tutores da fase anterior. Em York, o tutor principal foi Charles Wellbeloved, que era ministro da congregação Unitária da Saint Saviourgate Chapel. Posteriormente, dois novos tutores foram contratados: John Kenrick, para História e Letras Clássicas, e William Turner Junior, para Matemática e Ciências, sendo este último depois substituído por William Hincks. Charles Wellbeloved, como ministro Unitário, era da mesma escola de Joseph Priestley e adotou o mesmo "encargo solene" que o Dr. John Taylor utilizava para divulgar, entre os alunos da Warrington Academy, os princípios da liberdade religiosa, da liberdade de pensamento, da valorização da razão e da igualdade de direitos. ${ }^{31}$

Em 1817, o Manchester College-York divulgava um prospecto para o grande público, assinado pelo seu então Presidente, Thomas Robinson, em que procurava apresentar os seus princípios de "educação liberal para a juventude em geral, sem nenhuma distinção de confissão partidária ou religiosa, isenta de qualquer credo político ou subscrição doutrinária". ${ }^{32} \mathrm{Na}$ realidade, esse prospecto reiterava a tradição de ensino iniciada na Warrington Academy, comprometendo-se também a oferecer os dois tipos de cursos iniciados naquela antiga instituição: "o curso de instrução para o Ministério Cristão" que compreendia 5 anos e o curso integral para "Estudantes Leigos" com 3 anos de duração. No prospecto, era ainda apresentado o "Plano de Estudos" do curso de 3 anos, cujo objetivo maior era

(...) conduzir aqueles que estavam destinados às outras profissões eruditas através de um curso apropriado de estudos preparatórios; ou para capacitar os que estão destinados para a vida comercial a sustentar com a maior respeitabilidade a reputação do comerciante britânico. ${ }^{33}$

De acordo com o prospecto do Manchester College, o "Plano de Estudos" do curso de 3 anos se distribuía da seguinte maneira:

No primeiro ano, os Estudantes são instruídos no Grego e no Latim Clássicos, em História Antiga e Composição, e nos Elementos de Geometria Plana, Álgebra, e Trigonometria. No segundo ano, eles prosseguem com o Grego e o Latim

31 Cf. WATTS, op. cit.; e MANCHESTER..., op. cit., p. 5 e 9-10.

32 Cf. MACHESTER COLLEGE, op. cit., p. 8.

33 Ibid. 
Clássicos, e a prática de Composição, e acompanham um curso de História Moderna, em cuja atividade a atenção deles está particularmente direcionada para a História dos Princípios da Constituição Inglesa. Eles são instruídos na Geometria dos Sólidos; nas Seções Cônicas; na Doutrina da Esfera; e nas partes mais avançadas da Álgebra. Também são dadas aulas sobre a Filosofia da Mente e Lógica.

No terceiro ano, eles são mais profundamente instruídos no Grego e no Latim Clássicos, e nas 'Belas Letras'; em algumas das mais avançadas seções da Ciência Matemática, particularmente no método das Fluxões, e no Sistema Newtoniano de Astronomia Física. Eles também são introduzidos num amplo curso de estudos sobre Ética, Jurisprudência, e Economia Política; e são ministradas Conferências acerca das Evidências da Religião Natural e Revelada. Um amplo curso de Filosofia Natural e Experimental faz parte da atividade tanto do segundo como do terceiro Períodos Letivos. ${ }^{34}$

O "Plano de Estudos" do Manchester College-York afirmava, mais detalhadamente do que as instituições de ensino que lhe antecederam, um interesse formal pelas Ciências (Matemática, Física, Astronomia) e assuntos vinculados ao mundo dos negócios. Todavia, à medida em que o século XIX avançava, a perspectiva de um ensino prático, associado às necessidades da indústria, do comércio e das finanças ou mesmo de um ensino preparatório para os futuros médicos, foi substituída por uma outra não menos importante (no que se relaciona às novas descobertas científicas), mas vinculada aos interesses em Geologia, Botânica e Arqueologia que eram cultivados pelos tutores da instituição. O próprio Charles Wellbeloved, paralelamente ao ministério religioso e ao ensino no College, era um competente antiquário, chegando ao posto de Curador de Antiguidades da Yorkshire Philosophical Society. ${ }^{35}$

Além dessa mudança, uma outra alteração de grande magnitude se manifestou na vida do Manchester College-York. Diferentemente das instituições de ensino que lhe antecederam, que possuíam como principal base de sustentação a "Comunidade Dissidente" do Norte da Inglaterra, o Manchester College York tornou-se menos "regionalista" e um número muito mais significativo de estudantes vindos do Sul do país passou a fazer parte

34 Cf. MANCHESTER COLLEGE, op. cit.

35 Cf. RAYMOND; PICKSTONE, op. cit., e MANCHESTER COLLEGE, op. cit., p. 11. 
de seu corpo discente. Nos anos 1820, essa instituição transformou-se numa escola para os filhos dos Unitários mais ricos, perdendo, talvez, o vigor na defesa dos princípios do liberalismo radical e democrático de seus fundadores. ${ }^{36}$

\section{AS SOCIEDADES CINTÍFICAS E FILOSÓFICAS: A LUNAR SOCIETY E LITERARY AND PHILOSOFICAL SOCIETY OF MANCHESTER}

Um outro fenômeno cultural típico do século XVIII britânico foi a proliferação de sociedades científicas e literárias pelas diversas cidades do interior, cujo objetivo maior era a promoção das Ciências e das Artes nas suas próprias regiões. Muitas dessas sociedades foram criadas a partir de uma atitude crítica aos destinos da Royal Society de Londres, que perdera o entusiasmo dos seus anos iniciais e tornara-se, também, uma instituição altamente fechada e conservadora, ou um "clube londrino" como chamavam seus mais ferrenhos detratores. Essa "provincianização" das sociedades científicas e literárias foi maior na segunda metade do século e muito contribuiu para a atitude crítica de seus membros às novidades filosóficas e científicas produzidas pela Ilustração francesa na primeira metade e em meados do século, ajudando a estabelecer uma postura mais liberal, na forma desses homens encararem o mundo e a vida político-social.

As sociedades científicas e literárias mais importantes da segunda metade do século XVIII foram a Lunar Society (Sociedade Lunar), fundada em Birmingham por volta de 1765, pelo industrial metalúrgico Matthew Boulton, e a Literary and Philosophical Society of Manchester (Sociedade Filosófica e Literária de Manchester), fundada naquela cidade por volta de 1780. Essas instituições foram criadas por homens das regiões industriais

36 O Manchester College funcionou até 1840 na cidade de York, quando foi transferido para Manchester, tornando-se o Manchester New College, que funcionou até 1853. Neste ano, a instituição de ensino foi transferida para Londres, passando a se chamar Manchester New College-London, mantendo suas atividades nessa cidade até 1889, quando foi definitivamente transferido para Oxford, para o antigo "coração do establishment", tornando-se, já no século XX, uma das tantas unidades da Universidade de Oxford e passando a ser conhecido como Manchester College-Oxford. Sobre o restante da trajetória do Manchester College, ver: MANCHESTER COLLEGE, op. cit.; e MANCHESTER..., op. cit. 
que, em sua grande maioria, tiveram uma educação nas Academias NãoConformistas e se tornaram cientistas ou industriais respeitáveis.

A Lunar Society de Birmingham localizava-se justamente em West Midlands, região da metalurgia e da indústria pesada inglesa. Seus encontros e reuniões realizavam-se, uma vez por mês, na casa de um de seus membros, em geral numa segunda-feira, nas noites de lua cheia (daí o nome da sociedade), quando era possível achar com facilidade não só o caminho de ida para as reuniões, como também o caminho de volta para a casa. Entre os membros mais destacados da Lunar Society, estavam, além de seu fundador Matthew Boulton, seu sócio e inventor James Watt, o médico, poeta e naturalista Erasmus Darwin (avô de Charles Darwin), o industrial do ramo de cerâmica Josiah Wedgwood, o industrial do ramo químico James Keir, o fabricante de produtos de ferro Samuel Galton Junior (que foi expulso da seita Quaker por produzir revólveres), o fabricante de instrumentos John Whitehurst, o impressor John Baskerville, o engenheiro William Murdoch (que trabalhava para Boulton e Watt e inventou a iluminação a gás e a locomotiva a vapor), o botânico e médico Jonathan Stokes, o químico, professor e escritor Joseph Priestley, os médicos William Withering e William Small, os literatos Thomas Day e Richard Lovell Edgeworth e o reverendo Robert Augustus Johnson. ${ }^{37}$

As reuniões da Lunar Society sucederam-se regularmente até 1791, quando eclodiu, em Birmingham, uma revolta dos Anglicanos e Realistas contra os Não-Conformistas e os que apoiavam a Revolução Francesa, ou seja, diversos membros daquela sociedade, que praticamente deixou de existir e seus membros foram perseguidos e obrigados a deixar a cidade após a revolta, também conhecida como "Birmingham Riots" ou "Priestley Riots". Joseph Priestley, obviamente, esteve no epicentro da perseguição dos

37 Cf. MASON, op. cit., p. 285-286; e INDUSTRIAL Revolution: a documentary history. Series one. The Boulton and Watt Archive and the Matthew Boulton Papers from the Birmingham Central Library. Part I: Lunar Society correspondence (A listing and guide to the Microform Collection). Marlborough: Adam Matthew Publications, 1993. p. 15-20. Um estudo aprofundado da Lunar Society é o já clássico livro de SCHOFIELD, R. E. The Lunar Society of Birmingham. A social history of provincial science and industry in eighteenth-century England. Oxford: Clarendon Press, 1963. Existe ainda um número especial do University of Birmingham Historical Journal (v. 11, n. 1, Birmingham, 1967) dedicado à sociedade, com o tradicional título "The Lunar Society of Birmingham" e artigos de diversos autores. Para um resumo da trajetória da Lunar Society e das atividades dos seus membros, ver também: CADBURY, P. S. The Lunar Society of Birmingham. Bicentenary. Londres: University of London Press, 1966; e CADBURY, P. S. Bicentenary celebrations. Lunar Society exhibition. Birmingham: The Library of University of Birmingham, 1966. 
Anglicanos e Realistas devido a sua fervorosa crença Unitária (já uma dissidência mais radical do Presbiterianismo), que defendia com intransigência os princípios liberais da igualdade de direitos, da tolerância religiosa e da racionalidade da fé. Priestley teve sua casa invadida e incendiada por uma multidão de revoltosos, que também destruíram completamente sua biblioteca e seus equipamentos científicos. Como o clima de insegurança pessoal continuou após a revolta, Priestley e toda a sua família foram obrigados a emigrar para os Estados Unidos, em 1794. ${ }^{38}$

Depois de 1791, as reuniões da Lunar Society continuaram a ocorrer, mas era notório o clima de desânimo de seus participantes, amedrontados pelo ataque dos tradicionalistas Anglicanos e Realistas. Há indícios de que as reuniões da sociedade foram realizadas até 1802, mas nesses anos finais, houve uma redução do número de seus membros em função da morte de muitos deles (Day, Small, Johnson, Wedgwood, Whithering e Whitehurst) ou da mudança de residência para fora da região de Birmingham (Darwin, Edgeworth, Priestley e Stokes). Além disso, para não sofrerem represálias ou o ataque direto aos seus negócios que prosperavam enormemente, Matthew Boulton e James Watt, ainda como os grandes animadores da sociedade, passaram a ter uma atitude muito mais cautelosa, o que certamente influenciou o arrefecimento dos ânimos dos demais membros da Lunar Society e propiciou o seu declínio. ${ }^{39}$

A Lunar Society manteve intensa relação com o círculo de intelectuais norte-americanos reunido em torno de Benjamin Franklin, o grande estadista e cientista preocupado com o fenômeno da eletricidade. Franklin era amigo e correspondente dos membros da sociedade, especialmente Matthew Boulton, a quem visitou, em Birmingham, diversas vezes. Durante a Guerra de Independência dos Estados Unidos (1776-1783), o relacionamento e a correspondência de Franklin com os membros da Lunar Society foram reduzidos drasticamente, mas a amizade com o norte-americano foi fundamental para que alguns deles manifestassem a sua simpatia pela causa das "Treze Colônias". Inclusive, foi Benjamin Franklin quem apresentou a Matthew Boulton, através de uma carta de 22 de maio de 1765, o Dr. William Small que tinha sido professor de Filosofia Natural no College of William and Mary, da Virgínia, e teve entre seus alunos mais brilhantes Thomas Jefferson, o terceiro presidente dos Estados Unidos. A chegada do Dr. Small a Birmingham teve um efeito catalisador e contribuiu para a articulação mais

38 Sobre as revoltas de Birmingham, ver BIRD, V. The Priestley Riots, 1791, and the Lunar Society. Birmingham: [s. n.], 1994.

39 Cf. MASON, op. cit., p. 285-286. 
sistemática do grupo dos "gigantescos filósofos" da região, como os definiu Erasmus Darwin, e a constituição da própria Lunar Society. Foi essa conexão dos membros da sociedade com os círculos intelectuais e políticos norteamericanos que facilitou, mais tarde, a mudança de Joseph Priestley para os Estados Unidos e sua residência na Pensilvânia, tornando-se amigo de Thomas Jefferson. ${ }^{40}$

A importância da Lunar Society, no cenário histórico e científico da Inglaterra do final do século XVIII, foi assinalada por um dos maiores estudiosos dessa sociedade provincial, o historiador Robert E. Schofield, para quem:

Mais do que qualquer outro único grupo, a Sociedade Lunar de Birmingham representou as forças de mudança da Inglaterra do final do século XVIII, porque a Sociedade Lunar era um brilhante microcosmo daquela comunidade dispersa de manufatureiros provinciais e homens profissionais que encontraram a Inglaterra como uma sociedade rural, com uma economia agrícola, e a deixaram urbana e industrial. Uma improvável e 'revolucionária' sociedade, nunca antes alcançada. Foi um pequeno grupo, formado através dos anos de apenas quatorze membros (...) Eles não eram aquela espécie de homens de guarnecer as barricadas ou fazer discursos inflamados em tribunas políticas. A revolução que eles forjaram foi mais insidiosa - e mais permanente - do que aquela criada por seus pares franceses, porque estes homens foram os precursores da Revolução Industrial.

Eles se encontravam para jantar e discutir, na casa de um dos membros, uma vez por mês na tarde da segunda-feira mais próxima da ocasião de lua cheia - daí o nome Sociedade Lunar, mas isto era o menos importante, a parte meramente social de suas atividades. Muitos deles residiam perto de Birmingham, e podiam se comunicar diariamente; quando isso era impossível, eles escreviam um para o outro. Juntos eles formaram uma base de intercâmbio para as idéias que transformaram o seu país material, social e culturalmente no espaço de uma geração. Eles eram homens de diversas especialidades e suas discussões variavam amplamente, mas seu principal interesse mútuo eram as ciências, puras e aplicadas - particularmente aplicadas aos problemas da indústria. ${ }^{41}$

40 Cf. INDUSTRIAL..., op. cit., p. 112 e 182.

41 Cf. SCHOEFIELD, op. cit., p. 3. 
A Literary and Philosophical Society of Manchester, também conhecida abreviadamente como Lit. and Phil., foi fundada a partir das reuniões que cientistas e industriais realizavam na Warrington Academy, constando da sua lista de sócios fundadores mais de 40 pessoas. Esta instituição era muito maior e mais organizada do que a Lunar Society, sendo suas reuniões registradas em atas a partir de 1781 e os trabalhos apresentados, nesses eventos ou à direção da entidade, passaram a ser publicados a partir de 1785, com o título Memoirs of the Literary and Philosophical Society of Manchester. O seu primeiro presidente foi o médico Thomas Percival, que estudou na Warrington Academy, sob a orientação de Joseph Priestley, e o seu primeiro secretário foi o farmacêutico Thomas Henry. Nos seus primeiros tempos, a Lit. and Phil. teve como sócio mais importante o químico John Dalton, que mais tarde chegou a presidir a instituição por um longo período (1817-1844). ${ }^{42}$

No prefácio do primeiro volume das Memoirs, em 1785, o Dr. Thomas Percival assinalava a clara importância que as sociedades filosóficas e literárias tinham para a produção e divulgação do conhecimento na Europa e como estas deveriam se espalhar pelas diversas regiões da Inglaterra, para que a promoção das "Ciências" e das "Artes" não ficasse confinada em Londres, ou mais explicitamente na Royal Society:

As numerosas Sociedades para a promoção da Literatura e da Filosofia que foram, formadas em diferentes partes da Europa, no curso dos séculos passado e presente, têm sido não apenas o meio de uma difusão mais extensiva do conhecimento, como têm contribuído para produzir um número maior de descobertas importantes do que tem acontecido em qualquer outro espaço de tempo semelhante.

(...)

Embora, na França, sociedades com estes objetivos fossem criadas em diversas províncias, na Inglaterra elas têm sido quase que confinadas à Capital; e por maiores que sejam as vantagens resultantes das pesquisas das pessoas eruditas que estão associadas em Londres, parece provável que o grande fim das suas instituições, a promoção das artes e das ciências, possa ser mais largamente estendido através da formação de sociedades, com uma visão idêntica, nas principais cidades deste reino. ${ }^{43}$

42 Cf. MASON, op. cit., p. 286.

43 Cf. SMITH, R. A. A centenary of science in Manchester. For the hundredth year of the Literary and Philosophical Society of Manchester. Londres: Taylor and Francis, 1883. p. 24-25. 
A presença de um químico como um sócio eminente da Manchester Phil. não era uma mera coincidência, pois a Química era um campo de conhecimento da maior importância para a indústria têxtil de Manchester e todo o Lancashire (condado onde se encontrava a cidade), principalmente para o descoloramento e o tingimento dos tecidos. Apesar da importância da Química Teórica e Prática estar sublinhada no estatuto da sociedade, conhecido como "Laws and Regulations for the Government of the Literary and Philosophical Society of Manchester" ("Leis e Regulamentos para o Governo da Sociedade Literária e Filosófica de Manchester"), a Filosofia Natural, a Literatura, as Leis Civis, a Política Geral, o Comércio e as Artes também eram campos de conhecimento de interesse para os seus associados.

A "Lei" número VIII do estatuto da Lit. and Phil. estabelecia não apenas as áreas de interesse da sociedade, como também, numa atitude de moderação e precaução política, definia as matérias que não poderiam ser abordadas de maneira alguma em suas reuniões:

Que os assuntos de discussão compreendem filosofia natural, química teórica e experimental, literatura refinada, lei civil, política geral, comércio e as artes. Todavia, religião, os ramos práticos da física, e política britânica, são considerados proibidos; e o presidente pronunciará o seu veto quando eles forem introduzidos. $^{44}$

Diversos membros da Lit. and Phil. também apoiaram efusivamente a Revolução Francesa. Inclusive, dois deles, Thomas Cooper e James Watt Junior, chegaram a ser eleitos deputados para a Assembléia Nacional francesa. Esta franca simpatia de um número significativo de seus associados para com a Revolução Francesa acabou trazendo sérias dificuldades para a Lit. and Phil. no ano de 1791, quando também eclodiram na cidade as "King and God Riots" ("As Revoltas do Rei e de Deus"). Todavia, como era mais moderada, precavida e organizada do que a Lunar Society, os membros da Manchester Phil. não foram tão atacados e perseguidos quanto os seus companheiros de Birmingham. A Lit. and Phil. sobreviveu e, durante o século XIX, constituiu-se numa respeitável instituição científica da Grã-Bretanha, tornando-se um modelo e referência obrigatória para as outras instituições congêneres, fundadas no século $X X$, o que lhe possibilitou chegar até os nossos dias em pleno funcionamento e com bastante respeitabilidade. ${ }^{45}$

44 Cf. SMITH, op. cit., p. 29.

45 Cf. MASON, op. cit., p. 287. 
Não se pode deixar de mencionar ainda a Philosophical Society of Edinburgh (Sociedade Filosófica de Edimburgo), importante sociedade fundada na Escócia, em 1732, que desfrutava do clima de maior liberdade e tolerância religiosa que existia nos ambientes intelectuais daquela parte da Grã-Bretanha. Todavia, foi na segunda metade do século XVIII, que a Philosophical Society of Edinburgh alcançou o seu apogeu, em virtude da sua relação com os grandes nomes do Iluminismo Escocês, e a coroa britânica, em 1783, chegou a reconhecer a importância dessa instituição e concedeulhe uma Royal Charter (Carta Real), em que uma série de distinções eram assinaladas. Entre os membros mais famosos da Philosophical Society of Edinburgh estavam o filósofo David Hume, o economista Adam Smith, o professor de Medicina Joseph Black, o professor de Geologia James Hutton, o professor de Filosofia Natural John Playfair e o cientista amador James Hall. Essa sociedade tinha conexões diretas com as Universidades de Glasgow e Edimburgo que, na atmosfera intelectual do Iluminismo Escocês, estimularam o ensino das Ciências Naturais, sem abrir mão do ensino da Filosofia e de uma orientação mais teórica na investigação científica. A Universidade de Edimburgo tornou-se, inclusive, um dos grandes centros de ensino médico na segunda metade do século XVIII. Além disso, os cientistas escoceses, do mesmo modo que os "Não-Conformistas" ingleses, mantiveram relações diretas com as atividades industriais e inclusive um deles, James Hutton, tornou-se um importante industrial do ramo químico. ${ }^{46}$

\section{CONSIDERAÇÕES FINAIS}

Apesar do caráter inicial e exploratório das considerações apresentadas neste artigo, pode-se afirmar que a construção de uma sociedade industrial na Inglaterra, a partir dos anos 1780, contou com a formação prévia de uma mentalidade, nos meios eruditos e industriais, que considerava a mecanização do mundo social e produtivo como um fenômeno natural. Foi essa concepção que passou a anunciar a sociedade também como um "objeto" sujeito às "leis mecânicas" ou a uma "mecânica social". Se por um lado, este constituiu-se num dos principais caminhos para $a$ autonomização da sociedade frente a outros objetos de estudo, possibilitando, portanto, o nascimento das Ciências Sociais, por outro lado, tornou-se também num fator de constituição de um pensamento coletivo

46 Cf. MASON, op. cit., p. 287. 
que via a possibilidade do emprego de máquinas no processo produtivo, principalmente nas indústrias, como necessária para o atendimento das necessidades humanas e uma extensão lógica da idéia de um grande universo organizado sob leis mecânicas. A "machina-mundi" foi o pressuposto intelectual para se chegar à "machina faber" e à revolução das condições da produção material humana.

Entretanto, para que se realizasse a idéia de uma sociedade mecanizada, ou da produção industrial por meio de máquinas, foi primordial a atuação da Warrington Academy e da Manchester Academy (depois Manchester College), no desenvolvimento de uma nova concepção de ensino preparatório para a vida prática e em conformidade com os novos princípios científicos, e da Lunar Society e da Literary and Philosophical Society of Manchester, no estabelecimento de um efetivo diálogo entre os cientistas e industriais provincianos, responsáveis pela transformação da Inglaterra na primeira sociedade industrial do planeta. Dessa maneira, foram consolidadas as bases intelectuais não apenas da Revolução Industrial inglesa, como também da generalização da industrialização como elemento de mudança social e satisfação plena das necessidades humanas.

\section{RESUMO}

Neste artigo, pretende-se relacionar o processo de emergência da Revolução Industrial inglesa ao desenvolvimento de uma concepção filosófico-científica Mecanicista, consagrada pela Física Newtoniana e pela Ilustração no século XVIII, que concebiam a Natureza, o Mundo, e o Universo a partir de uma ordem mecânica objetiva e exterior ao Homem. No decorrer do século XX, a ampla divulgação do Mecanicismo possibilitou que essa concepção se tornasse uma das poderosas alavancas intelectuais da grande transformação técnicoprodutiva e social que se verificou na Inglaterra a partir dos anos 1780 - a Revolução Industrial.

Palavras-chave: mecanicismo, revolução, indústria, Inglaterra. 


\begin{abstract}
This article intends to associate the emergency of the English Industrial Revolution to the development of a mechanical, philosophical and scientific conception - consecrated by the Newtonian Physics and the Enlightenment in the 18th century -, which conceived the Nature, the World and the Universe as an objective, mechanical and external order to the Man. Throughout the 18th century, the wide divulgation of the Mechanism enabled it to become one of the powerfull intelectual levers of the Industrial Revolution, the process of technical, economic and social transformation that had taken place in England from the 1780's onwards.

Key-words: mechanism, revolution, industry, England.
\end{abstract}

\title{
REFERÊNCIAS
}

ASHTON, T. S. A revolução industrial. 1760-1830. Lisboa: Publicações Europa-América, 1977.

BIRD, V. The Priestley Riots, 1791, and the Lunar Society. Birmingham: [s. n.], 1994.

BROADIE, A. (Org.). The Scottish Enlightenment. An anthology. Edimburgo: Canongate Books, 1997.

CADBURY, P. S. The Lunar Society of Birmingham. Bicentenary. Londres: University of London Press, 1966.

CADBURY, P. S. Bicentenary celebrations. Lunar Society exhibition. Birmingham: The Library of University of Birmingham, 1966.

CASINI, P. Newton e a consciência européia. São Paulo: Unesp, 1995.

CASSIRER, E. La filosofia de la Ilustración. México: Fondo de Cultura Económica, 1984.

DITCHFIELD, G. M. Unitarianism. In: BLACK, J.; PORTER, R. A dictionary of eighteenth-century world history. Oxford: Blackweel Publishers, 1994.

GAY, P. The Enlightenment. The rise of modern paganism. Nova York-Londres: W. W. Norton \& Company, 1995.

HAMPSON, N. The Enlightenment. An evaluation of its assumptions, attitudes and values. Londres: Penguin Books, 1990.

HAMPTON, D. Arianism. In: BLACK, J. PORTER, R. A dictionary of eighteenthcentury world history. Oxford: Blackweel Publishers, 1994.

HANKINS, T. L. Science and the Enlightenment. Cambridge-UK: Cambridge University Press, 1997.

HOBSBAWM, E. J. A era das revoluções: 1789-1848. Rio de Janeiro: Paz e Terra, 1977. 
HOF, U. I. The Enlightenment. Oxford: Blackwell Publishers, 1994.

INDUSTRIAL REVOLUTION: a documentary history. Series one. The Boulton and Watt Archive and the Matthew Boulton Papers from the Birmingham Central Library. Part I: Lunar Society correspondence (A listing guide to the Microform Collection). Marlborough: Adam Matthew Publications, 1993.

JACOB, M. C. Scientific culture and the making of the industrial west. Oxford-New York: Oxford University Press, 1997.

LANDES, D. S. Prometeu desacorrentado. Transformação tecnológica e desenvolvimento industrial da Europa Ocidental, desde 1750 até a nossa época. Rio de Janeiro: Nova Fronteira, 1994.

MANCHESTER COLLEGE. 1786-1986. A bicentenary exhibition organised by Manchester College Oxford at the Bodeleian Library. Oxford: Manchester College, 1986.

MANTOUX, P. La révolution industrielle au XVIIIe. siècle. Paris: Génin, 1959.

MASON, Stephen F. A history of sciences. Nova York: Collier Books, 1962.

MATHIAS, Peter. The first industrial nation. An economic history of Britain, 17001914. Londres-Nova York: Routledge, 1983.

MCLACHLAN, Herbert. Warrington Academy: its history and influence. Manchester: Chetham Society, 1943.

RAYMOND, J.; PICKSTONE, J. The Natural Sciences and the learning of English Unitarians: an exploration of the roles of Manchester College. In: SMITH, B. (Org.). Truth, liberty, religion. Essays celebrating two hundred years of Manchester College. Oxford: Manchester College Oxford, 1986.

RIOUX, J. P. A revolução industrial: 1780-1880. São Paulo: Pioneira, 1975.

SCHOFIELD, R. E. The Lunar Society of Birmingham. A social history of provincial science and industry in eighteenth-century England. Oxford: Clarendon Press, 1963.

SMITH, R. A. A centenary of science in Manchester. For the hundredth year of the Literary and Philosophical Society of Manchester. Londres: Taylor and Francis, 1883.

TURNER, W. The Warrington Academy: 1757-1786. Warrington: Library and Museum Committee, 1957.

UNIVERSITY OF BIRMINGHAM HISTORICAL JOURNAL. Birmingham, v. 11, n. 1, 1967. Número especial.

WATTS, R. Manchester College and education. 1786-1753. In: SMITH, B.(Org.). Truth, liberty, religion. Essays celebrating two hundred years of Manchester College. Oxford: Manchester College Oxford, 1986.

WEBB, R. K. The Unitarian Background. In: SMITH, B. (Org.). Truth, liberty, religion. Essays celebrating two hundred years of Manchester College. Oxford: Manchester College Oxford, 1986.

WYKES, D. Sons and subscribers: lay support and the College, 1786-1840. In: SMITH, B. (Org.). Truth, liberty, religion. Essays celebrating two hundred years of Manchester College. Oxford: Manchester College Oxford, 1986. 